\title{
Cocriação de Valor em Sala de Aula como um Antecedente do Engajamento dos Estudantes de Instituição de Ensino Superior
}

\section{Value Co-creation in the Classroom as an Antecedent of Student Engagement of Higher Education Institution}

\author{
Clécio Falcão Araujo \\ Ricardo Saraiva Frio \\ Caroline da Rosa \\ Patricia Rodrigues da Silva
}

A concepção da lógica dominante de serviço pode ser compreendida a partir do contexto do ensino superior. Em um ambiente de sala de aula, alunos e professores podem cocriar valor contribuindo para um melhor aproveitamento das disciplinas e, consequentemente, maior engajamento dos alunos e melhor resultado para as universidades. Nesse sentido, o objetivo do presente estudo foi analisar o efeito da cocriação de valor em sala de aula como um antecedente do engajamento de estudantes de Instituição de ensino superior. A partir de uma amostra de 320 estudantes de universidades da região sul do Brasil e utilizando-se de modelagem de equações estruturais, os resultados apontaram que a cocriação de valor aumenta o engajamento dos estudantes com a disciplina. As descobertas também forneceram apoio empírico, demonstrando que o tipo de metodologia aplicada pelo professor exerce um papel moderador na relação entre a coprodução e o engajamento do aluno com a disciplina. Os resultados têm implicações para as universidades e para os professores ao instigar o desenvolvimento de metodologias que sejam centradas na cocriação de valor do aluno. Professores e gestores devem incentivar a cocriação de valor dos alunos, buscando maior engajamento nas disciplinas.

Palavras-chave: Cocriação de valor, Coprodução, Valor em uso, Engajamento, Metodologia ativa

The concept of the dominant service logic can be understood from the context of higher education. In a classroom environment, students and teachers can create value by contributing to a better use of subjects and, consequently, greater student engagement and better results for universities. In this sense, the objective of the present study was to analyze the effect of
Recebido em: 28/01/2021 Aprovado em: 26/05/2021

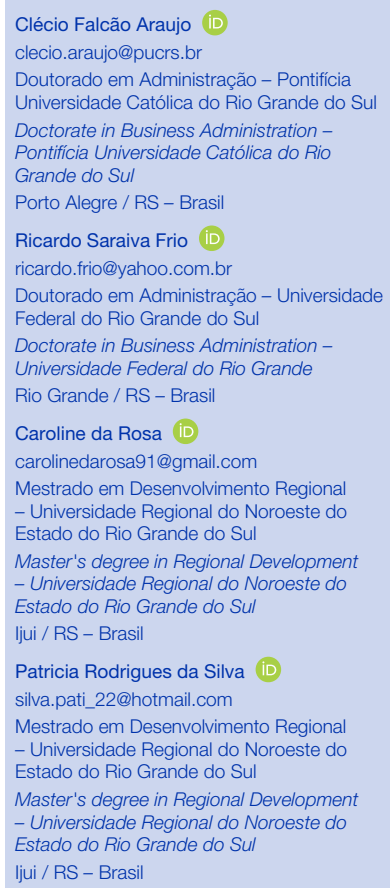


co-creation of value in the classroom as an antecedent of the student engagement of higher education institution. Based on a sample of 320 university students from the southern region of Brazil and using structural equation modeling, the results showed that the co-creation of value increases student engagement with the discipline. The findings also provided empirical support, demonstrating that the type of methodology applied by the teacher plays a moderating role in the relationship between co-production and student engagement with the discipline. The results have implications for universities and teachers by instigating the development of methodologies that are centered on co-creating student value. Teachers and managers should encourage student value co-creation, seeking greater engagement in the disciplines.

Keywords: Value co-creation, Co-production, Value in use, Engagement, Active methodology

\section{Introdução}

A concepção da lógica dominante de serviço pode ser compreendida a partir do contexto do ensino superior (DOLLINGER; LODGE; COATES, 2018), uma vez que os alunos podem ser cocriadores da dinâmica da sala de aula e, consequentemente, da sua própria aprendizagem. Bovill (2020) observa-se na literatura um crescente interesse do debate sobre clientes como parceiros na educação superior. Nesse contexto, temos como parceiros e cocriação são utilizados como sinônimos (BOVILL, 2020). A cocriação pode contribuir para a vantagem competitiva das instituições de ensino, uma vez que os alunos que interagem no processo de aprendizagem podem ter um aumento na sua satisfação, um melhor desempenho e se tornarem leais à instituição (HOFSTATTER, 2010).

A era do conhecimento exige das instituições de ensino superior metodologias sensíveis aos diferentes ritmos de cada indivíduo, nas quais o importante não é a explicação docente, mas o trabalho singular de cada aluno, seja de forma individual ou em cooperação (GÓMEZ, 2002). O modelo tradicional de ensino, baseado em transmissão e assimilação de conteúdo, geralmente não é capaz de provocar a reconstrução do modo de pensar e sentir dos alunos (GÓMEZ, 2002). Esse modelo associa-se, frequentemente, a uma aprendizagem passiva (FIDALGO-BLANCO et al., 2017).

As metodologias ativas vêm sendo utilizadas dentro das universidades, transformando o estudante no protagonista da sua aprendizagem (ELSHARNOU- 
BY, 2015; PAIVA et al., 2016, GUERRA; TEIXEIRA, 2016,). O uso de metodologias ativas transforma o ambiente de sala de aula, propiciando uma maior troca de conhecimentos e experiências entre alunos e professores ( GUERRA; TEIXEIRA, 2016, DOLLINGER; LODGE; COATES, 2018). Para um melhor aprendizado, diversas técnicas de ensino-aprendizagem vêm sendo empregadas, fazendo com que o aluno tenha um papel crucial no seu próprio aprendizado. Por outro lado, o valor percebido por este estudante só é observado quando o aluno está disposto a participar e contribuir nas atividades propostas (DOLLINGER; LODGE; COATES, 2018). Uma análise bibliométrica da literatura de metodologia ativa identificou um número crescente de publicações sobre o tema a partir de 2016 (SEGURA-ROBLES; PARRA-GONZÁLEZ; GALLARDO-VIGIL, 2020).

Grönroos (2008) define valor para os clientes como estar ou se sentir melhor após ter sido assistido por um processo de autosserviço ou um processo de serviço completo. O valor em uso, como o próprio nome pressupõe, advém dos processos geradores de valor dos consumidores. O foco muda, portanto, do que um produto ou serviço (aula) pode oferecer a um cliente (aluno) para as interações entre cliente e organização (universidade) e, mais especificamente, funcionários de linha de frente (professores) e os benefícios advindos desses processos.

Cada aluno apresenta peculiaridades quanto preferências de aprendizagem (OGUNMOKUN et al., 2021), neste cenário emerge a possibilidade do aluno coproduzir e cocriar valor com o provedor de serviço (ZEITHAML et al., 2020) e gerar um valor individual a partir dessa interação (VARGO; LUSCH, 2016). Ressalva-se que os conceitos de coprodução e cocriação, apesar de relacionados, são distintos (VARGO; LUSCH, 2016). A coprodução pressupõe uma atividade normativa do consumidor durante os processos com a organização, sendo um componente formativo à cocriação de valor (BUSSER; SHULGA, 2018; RANJAN; READ, 2016). A avaliação da cocriação de valor, a partir da lógica de serviço dominante, é identificada em distintos contextos e campos do conhecimento, dentre os quais a educação, verificando temas como engajamento e experiências de aprendizagem, por exemplo (VARGO; LUSCH, 2017).

$\mathrm{O}$ uso de metodologias ativas pelos professores tem o potencial de estimular nos alunos o sentimento de engajamento com as disciplinas (BERBEL, 2011). O engajamento pode ser compreendido como um estado psicológico que ocorre em 
virtude de experiências interativas e cocriativas dos clientes com um agente (BRODIE et al., 2011). Na medida em que um aluno esteja mais engajado com uma disciplina, poderá oferecer uma melhor contribuição para a sua dinâmica e, consequentemente, para o seu aprendizado e satisfação com o encontro de serviço (GRILLO et al., 2014).

Parte-se neste estudo, portanto, da concepção de que o aluno, ao ter um papel ativo em sala de aula, está contribuindo à cocriação de valor do ensino oferecido nas universidades. Diante do exposto, este estudo teve como objetivo analisar o efeito da cocriação de valor em sala de aula como um antecedente do engajamento dos estudantes de ensino superior. O presente estudo foi conduzido com 320 estudantes de universidades brasileiras do sul do País. Os resultados indicam que os elementos formadores da cocriação de valor auxiliam no aumento do engajamento do aluno.

O artigo está organizado da seguinte forma: a próxima seção fornece uma breve discussão sobre o engajamento do acadêmico com a disciplina, a cocriação de valor em sala de aula e a coprodução e o engajamento do estudante com a disciplina. A seguir, apresenta-se a explicação do método de pesquisa, que leva à discussão dos resultados. O artigo é concluído com as suas implicações teóricas e educacionais, bem como com um esboço das direções futuras de pesquisa.

\section{Referencial Teórico}

\section{ENGAJAMENTO DO ESTUDANTE COM A DISCIPLINA}

O conceito de engajamento é recente na literatura de marketing. Brodie et al. (2011) exploraram os fundamentos teóricos do Engajamento do Consumidor (EC). Da análise teórica derivaram cinco proposições fundamentais da lógica dominante do serviço (VARGO; LUSCH, 2004), as quais foram utilizadas para desenvolver uma definição geral de EC. Para os autores, o engajamento do consumidor diz respeito a um estado psicológico que ocorre em virtude de experiências interativas e cocriativas dos clientes com um agente. Nesse sentido, os conceitos de "envolvimento" e "participação" podem ser vistos como antecedentes do EC.

Hollebeek, Glynn e Brodie (2014), percebendo uma lacuna na literatura e buscando gerar maior conhecimento gerencial e insights teóricos, desenvolveram e va- 
lidaram uma escala sobre engajamento da marca do consumidor (Consumer brand engagement - CBE). Os autores definem engajamento da marca do consumidor como uma atividade cognitiva, emocional e comportamental, relacionada positivamente com a marca pelo consumidor. O engajamento do consumidor manifesta-se na dimensão cognitiva, afetiva e comportamental (DESSART; VELOUTSOU; MORGAN-THOMAS, 2016).

Vivek et al. (2014) desenvolveram uma conceituação tridimensional do construto de engajamento do consumidor (composto de atenção consciente, participação entusiasmada e conexão social). Com o estudo, identificaram que o constructo tem uma relação positiva com percepções de valor, percepções de benevolência, intenções futuras e comprometimento afetivo com a organização.

Como afirmam Vivek et al. (2014) somente iniciando e gerenciando conexões contínuas com os clientes, marcas e empresas podem esperar um engajamento mais profundo com os clientes, levando a relacionamentos duradouros. Clientes engajados não apenas auxiliam outros clientes a reconhecer as suas necessidades, mas também auxiliam a perceber como uma marca pode atendê-las, ofuscando os limites entre o papel de uma empresa e o papel de um cliente e constituindo a voz mais credível da marca.

Os autores supracitados corroboram no sentido de compreender o engajamento do consumidor como um processo que transcende o seu envolvimento com organizações e marcas. Um contexto que tem sido estudado por pesquisadores interessados na temática de serviços é o do ensino superior. Para Grillo et al. (2014) a sala de aula tem sido interpretada como um ambiente de encontro de serviço altamente propício à cocriação de valor. Nesse sentido, o engajamento emerge como uma "mola propulsora" que faz o estudante, por meio de processos interativos com professor e outros alunos, auxiliar no seu próprio aprendizado e na melhoria dos encontros de serviços da sala de aula.

\section{COCRIAÇÃO DE VALOR EM SALA DE AULA}

A cocriação de valor oferece às organizações e à sua rede de atores oportunidades significativas de inovação a partir do processo de integração de recursos oferecidos pelos atores (FROW et al., 2015). De acordo com a perspectiva da lógica dominante em serviços, o papel dos clientes transformou-se de uma audiência 
passiva para uma participação ativa na cocriação da experiência de serviço, sendo o valor cocriado por múltiplos atores, sempre incluindo o beneficiário (cliente) (VARGO; LUSCH, 2016). Nesse sentido, o agir conjunto de alunos, corpo docente e funcionários de uma universidade permite a criação de resultados superiores àqueles gerados pela atuação da instituição no modelo tradicional, como a única geradora de valor para o usuário (aluno) (DOLLINGER; LODGE; COATES, 2018; FROW et al., 2015).

Dollinger, Lodge e Coates (2018) apresentaram o primeiro modelo conceitual de cocriação de valor no ensino superior. O modelo inclui os componentes de cocriação de valor, coprodução e valor em uso, podendo ser utilizado para orientar a prática do corpo docente e da administração no contexto do ensino superior. Para Ranjan e Read (2016) a cocriação de valor é um conceito bidimensional, o qual inclui a coprodução de valor, isto é, a proposição de valor criada ao lado do consumidor; e valor em uso, conceito subjacente à lógica dominante de serviço.

O estudo de Dollinger, Lodge e Coates (2018) parte da análise de Ranjan e Read (2016) para a cocriação de valor e aplica uma compreensão diferenciada da cocriação para o setor de ensino superior, modificando as duas dimensões de cocriação (coprodução e valor em uso). Nesse sentido, o objetivo dos autores foi analisar como o valor da coprodução afeta o valor que ele vê ou usa e não como o aluno coproduziu proposições de valor dentro do ensino superior.

\section{A COPRODUÇÃO E O ENGAJAMENTO DO ESTUDANTE COM A DISCIPLINA}

A coprodução de valor indica ações esperadas dos consumidores durante o processo de interação com a empresa, sendo facultado ao estudante realizar ou não essas atividades (VARGO; LUSCH, 2016). A coprodução se refere, então, a atividades parciais realizadas pelo usuário (RANJAN; READ, 2016). A participação (coprodução) ativa do consumidor durante a interação com as empresas é um componente da cocriação de valor (TOMMASETTI; TROISI; VESCI, 2017).

Estes processos de interatividade podem ser observados no contexto de provisão de serviço de universidades, analisando a dinâmica existente em sala de aula entre professor (es) e alunos. Neste ambiente, os alunos cocriam valor, uma vez que podem apresentar questionamentos e contribuições pessoais, apresentar seminários e trabalhos em grupos, apresentar sugestões ao processo avaliativo 
da disciplina e ao funcionamento geral da universidade por meio de ouvidorias e avaliações e participar, de um modo geral, no decorrer das aulas (MAVONDO; TSARENKO; GABBOTT, 2004).

Ranjan e Read (2016) identificaram, após rigorosa revisão de literatura, que o conceito de cocriação de valor possui duas dimensões conceituais primárias: coprodução e valor em uso. Cada uma dessas dimensões, por sua vez, possui três elementos conceituais subjacentes. A dimensão da coprodução é formada pelos elementos de conhecimento compartilhado, equidade e interação; já a dimensão do valor em uso é composta pelos elementos de experiência, personalização e relacionamento.

O conhecimento compartilhado constitui a base da vantagem competitiva e do crescimento econômico (VARGO; LUSCH, 2004). Para Dollinger, Lodge e Coates (2018) o compartilhamento de conhecimento entre organizações e consumidores ocorre por diversos mecanismos para permitir que a organização colete e analise as opiniões e o conhecimento dos consumidores em relação à proposta de valor. O gerenciamento do conhecimento dos clientes possibilita maior percepção acerca das oportunidades de mercados emergentes, melhoria de processos estabelecidos e maior criação de valor para a organização, acionistas e consumidores (GIBBERT; LEIBOLD; PROBST, 2002).

O papel da empresa é servir como facilitadora de valor(GRÖNROOS, 2008). Nesse sentido, ao fornecer aos clientes produtos e serviços facilitadores de valor como recursos de entrada para os processos de geração de valor dos clientes, a empresa envolve-se indiretamente na criação de valor dos clientes. A equidade é necessária, portanto, para que possam ocorrer os processos de cocriação de valor. Em um contexto de ensino superior, significa afirmar que os alunos possuem igual acesso para compartilhar seu conhecimento, tanto na relação empresa-consumidor como nas relações entre alunos (DOLLINGER; LODGE; COATES, 2018).

Uma lógica de negócios baseada em serviços vai incluir, portanto, interações que ocorrem entre a universidade e os alunos em suas ofertas de mercado (GRÖNROOS, 2008). O relacionamento é um dos pilares fundamentais dessa concepção (VARGO; LUSCH, 2004). Nesse sentido, para que possa haver a coprodução no ensino superior é necessária a equidade (acesso) e o compartilhamento de conhecimento entre os alunos e o(s) professor(es) (que está representando a universidade, 
como funcionário de linha de frente), e mesmo entre os alunos, por meio das interações (DOLLINGER; LODGE; COATES, 2018).

O denominador comum do foco central no relacionamento com o cliente é uma visão de troca impulsionada pelos benefícios percebidos pelo consumidor (VARGO; LUSCH, 2004). No que se refere à coprodução, como visto, é necessário existir a equidade (acesso) para que os conhecimentos dos alunos sejam compartilhados com os professores e demais alunos em sala de aula (interações). O engajamento do aluno, portanto, pode ocorrer em virtude de experiências interativas e cocriativas com a universidade. Diante do exposto, tem-se como hipótese deste estudo:

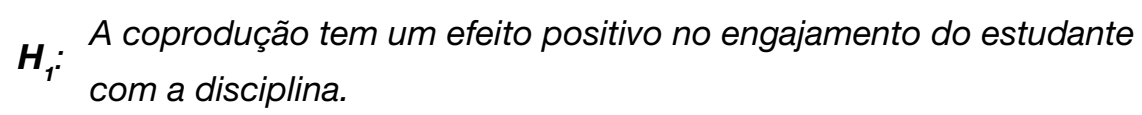

\section{VALOR EM USO E O ENGAJAMENTO DO ESTUDANTE COM A DISCIPLINA}

A coprodução, no entanto, não é suficiente para descrever o processo de cocriação de valor (DOLLINGER; LODGE; COATES, 2018). A discussão também precisa incluir as proposições de valor dos consumidores sobre os produtos e serviços e como estes são utilizados. Se a coprodução é o processo que ocorre entre usuários e organizações na concepção e entrega da proposta de valor dos produtos e serviços, o valor em uso pode ser compreendido como o valor atribuído pelos usuários uma vez que começam a utilizar o produto ou serviço coproduzido (DOLLINGER; LODGE; COATES, 2018).

Em um encontro de serviço, usuários utilizam suas habilidades e conhecimentos para cocriar valor. Como afirmam Vargo e Lusch (2004), as pessoas têm recursos operantes físicos e mentais, porém limitados ao suprimento de todas as suas necessidades. Precisam, portanto, realizar trocas dos seus diferentes serviços, a partir dessas habilidades. No marketing pensado em termos de processos contínuos, o consumidor é sempre envolvido na produção de valor (VARGO; LUS$\mathrm{CH}, 2004)$. Ranjan e Read (2016) identificaram que três elementos compõem o valor em uso: experiência, personalização e relacionamento.

A experiência dos consumidores com suas proposições de valor é importante tanto para a organização como para os consumidores (DOLLINGER; LODGE; COA- 
TES, 2018). O valor está na experiência de cocriação, que decorre da interação do consumidor com todos os elementos inerentes ao processo de consumo (PRAHALAD; RAMASWAMY, 2004). Assim, a criação de valor é definida pela experiência de consumidores específicos, em um ponto específico no tempo e no local, no contexto de um evento específico. Considerando essas características, os indivíduos e suas interações vão definir tanto a experiência quanto o valor derivado dela. Dollinger, Lodge e Coates (2018) afirmam que as experiências dos alunos podem ser um importante mecanismo para entender a qualidade do serviço educacional.

A personalização diz respeito à singularidade do processo de uso real ou percebido do produto ou serviço, que depende das características individuais do consumidor (RANJAN; READ, 2016). A proposta personalizada amplia a dimensão do valor percebido pelo consumidor (RANJAN; READ, 2016). Os consumidores podem se utilizar do consumo para sentirem-se bem sobre sua singularidade e sobre si mesmos (DEBERRY-SPENCE, 2008). Quando o valor em uso é percebido pelo cliente a criação de valor torna-se um processo contínuo e personalizado, o qual enfatiza as experiências (GRÖNROOS; VOIMA, 2013).

O relacionamento exerce um papel fundamental na relação entre a organização e seus clientes (DOLLINGER; LODGE; COATES, 2018). A cocriação envolve a busca de relações mutuamente benéficas entre profissionais de marketing e clientes, capacitando-os a colaborarem no processo de produção (BONSU; DARMODY, 2008). No contexto do ensino superior, diz respeito às relações entre alunos e professores, que devem permitir o espaço para o compartilhamento de conhecimento visando a cocriação de valor. A partir do tipo de relação que tem com o professor, o aluno pode ter diferentes proposições de valor (DOLLINGER; LODGE; COATES, 2018).

O conceito de valor em uso, portanto, é o valor que o consumidor atribui ao serviço em seu processo de cocriação de valor, uma vez que os atores não podem criar valor sozinhos, e sim, propor o valor (VARGO; LUSCH, 2016). O ambiente de sala de aula tem sido interpretado como altamente propício à cocriação de valor (GRILLO et al., 2014), que pode se dar a partir do engajamento dos alunos. Diante do exposto, supõe-se que:

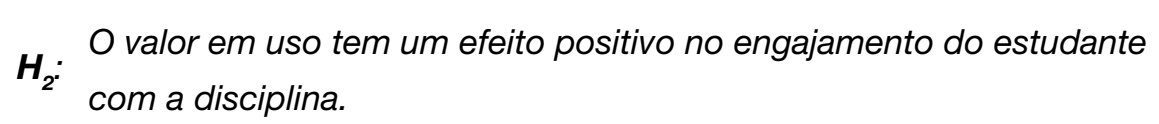




\section{EFEITO MODERADOR DA METODOLOGIA DE ENSINO}

A presente pesquisa avaliou dois tipos de metodologias de ensino: metodologia ativa e metodologia não ativa. A metodologia ativa corresponde a aulas mais interativas do que as aulas tradicionais, com uso de seminários, pesquisas e estudo de caso, por exemplo. Metodologia não ativa sugere aulas expositivas em sua totalidade. A lógica de serviço dominante pressupõe que a empresa deve fazer a oferta de valor e o consumidor vai aceitar (ou não) cocriar valor com a organização (VARGO; LUSCH, 2016). Nota-se que ambas as metodologias apontam para uma oferta de valor. A metodologia ativa pressupõe um maior envolvimento do estudante. Contudo, espera-se que a metodologia não ativa gere um maior impacto da coprodução no engajamento.

O consumidor deseja participar dos processos da empresa e busca sempre um papel ativo (PRAHALAD; RAMASWAMY, 2004). Uma vez que, por meio da cocriação, os diferentes conhecimentos e recursos que os alunos possuem, podem auxiliar a interagir em conjunto com os professores da universidade para criar resultados mais integrados e superiores do que se apenas um grupo tentasse satisfazer as necessidades do outro (DOLLINGER; LODGE; COATES, 2018).

Observa-se que a coprodução e o valor em uso já pressupõem maior envolvimento do aluno no processo de criação de valor da disciplina (RANJAN; READ, 2016). Ao utilizar uma metodologia ativa, o papel do aluno é suprimido pelo método de aula, tornando sua participação secundária à metodologia.

A utilização da metodologia ativa por si gera maior engajamento do estudante na disciplina (MATZEMBACHER; GONZALES; DO NASCIMENTO, 2019), porém elimina o protagonismo do papel do acadêmico. Dessa forma, quando aplicada a metodologia ativa, o estudante deve apresentar um papel ativo, não levando o aluno a exercer o papel de protagonista na coprodução na disciplina. Quando existe a utilização de uma metodologia não ativa, o papel do consumidor torna-se passivo, incentivando que o mesmo busque maior preponderância na disciplina. Assim:

O tipo de metodologia modera a efeito entre (a) valor em uso e (b)

$\boldsymbol{H}_{3}$ : coprodução no engajamento do estudante. As relações propostas são mais salientes para metodologia não ativa do que ativa. 
As hipóteses apresentadas, que configuram o modelo teórico da pesquisa, podem ser observadas na Figura 1.

Figura 1 Modelo teórico da pesquisa

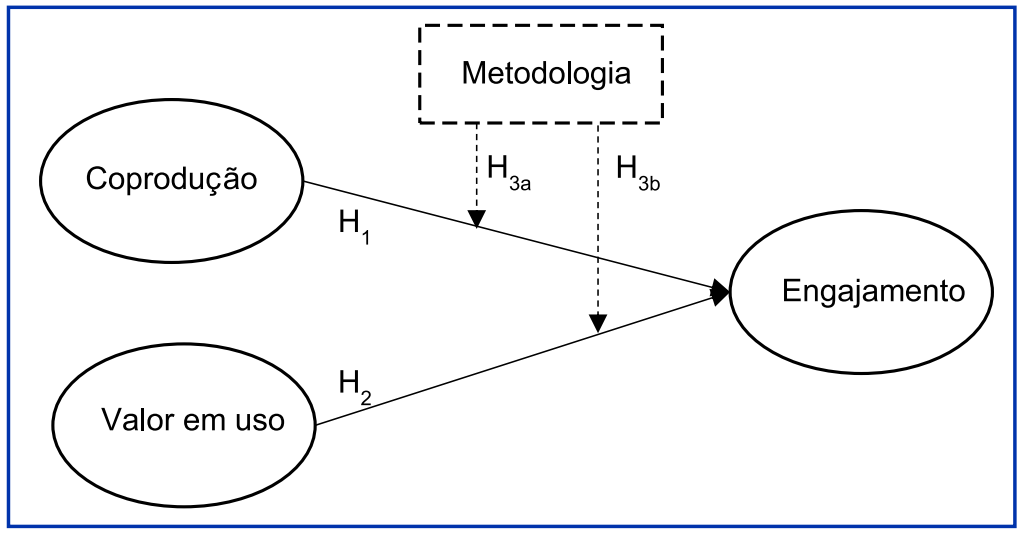

Fonte: elaborado pelos autores

\section{Método}

\section{COLETA DE DADO E AMOSTRA}

A coleta de dados deste estudo empírico teve um corte transversal. A pesquisa foi realizada nos meses de junho a agosto (2019) abrangendo três diferentes universidades brasileiras do sul do País. A pesquisa foi baseada na participação voluntária e todas as respostas foram anônimas. Uma versão preliminar do instrumento de coleta de dados foi pré-avaliada por um grupo de estudantes. Foi solicitado que eles fornecessem um feedback sobre a clareza, abrangência, adequação, validade de face e legibilidade.

Para a obtenção da amostra, inicialmente utilizou-se um mailing disponibilizado pela universidade. Devido à baixa taxa de adesão dos respondentes, uma segunda estratégia foi adotada com uma coleta através de caneta e papel em sala de aula. A amostra obtida válida foi de 320 estudantes de graduação e de pós-graduação. O estudo foi realizado em instituições privadas do Rio Grande do Sul. O perfil da amostra é apresentado na tabela 1. 
Tabela 1 Perfil da amostra

\begin{tabular}{|c|c|c|c|}
\hline & & Número & Percentual \\
\hline \multirow{2}{*}{$\begin{array}{l}0 \\
\stackrel{0}{5} \\
0 \\
0\end{array}$} & Graduação & 303 & 94.7 \\
\hline & Pós-graduação & 17 & 5.3 \\
\hline \multirow{4}{*}{$\stackrel{ }{\gtrless}$} & Tecnólogo & 70 & 21.9 \\
\hline & Licenciatura & 28 & 8.8 \\
\hline & Bacharelado & 205 & 64.1 \\
\hline & Mestrado/Doutorado & 17 & 5.3 \\
\hline \multirow{4}{*}{$\begin{array}{l}\frac{\pi}{3} \\
\frac{0}{0} \\
\frac{0}{0} \\
\frac{0}{2} \\
\sum\end{array}$} & Aulas expositivas & 180 & 56.3 \\
\hline & Método ativo & 91 & 28.4 \\
\hline & Pesquisas & 17 & 5.3 \\
\hline & Seminários & 32 & 10.0 \\
\hline \multirow{3}{*}{ 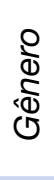 } & Masculino & 122 & 38.1 \\
\hline & Feminino & 191 & 59.7 \\
\hline & Não binário & 7 & 2.2 \\
\hline \multirow{4}{*}{ 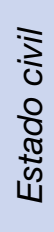 } & Solteiro & 237 & 74.1 \\
\hline & Casado & 63 & 19.7 \\
\hline & Divorciado & 5 & 0.6 \\
\hline & Outros & 15 & 4.7 \\
\hline
\end{tabular}

Fonte: elaborado pelos autores

\section{MEDIDAS}

A construção do instrumento de coleta de dados foi elaborada com base na revisão da literatura. A Cocriação em sala de aula foi mensurada por dois construtos reflexivos de segunda ordem, i) Valor em uso, e ii) Coprodução, baseada no estudo de Ranjan e Read (2016). A Coprodução é composta por três construtos de primeira ordem: Conhecimento Compartilhado (4 itens), Equidade (4 itens) e Interação (4 itens). Valor em uso é composto por três construtos de primeira ordem: Experiência (3 itens), Personalização (4 itens) e Relacionamento (4 itens). Ranjan e Read (2016) conceituam a cocriação como medida formativa. 
Contudo, no presente estudo optou-se por adaptar a mensuração para reflexiva. Observa-se que outros autores utilizam a concepção reflexiva para constructos de primeira ordem (por exemplo, MERZ; ZARANTONELLO; GRAPPI, 2018). Observa-se, ainda, que a cocriação faz com que o consumidor avalie vários fatores correlatos, justificando uma escolha reflexiva (BUSSER; SHULGA, 2018).

Howell, Breivick e Wilcox (2007) consideram que medidas formativas estão mais sujeitas a problemas de interpretação e que os constructos não são formativos ou reflexivos por natureza. Por fim, medidas formativas, usualmente, possuem menos relação entre si e representam a composição dos itens individuais no todo (HAIR et al., 2018).

A mensuração do Engajamento, estabelecida com base nos estudos de Vivek, et al. (2014) e Grillo et al. (2014), é composta por três construtos de primeira ordem: Entusiasmo (4 itens), Atenção (4 itens) e Interação social (4 itens). Os construtos foram traduzidos do inglês para o português por dois especialistas e adaptados ao contexto do estudo. Utilizou-se uma escala likert de 5 pontos, sendo que o ponto 1 expressava "discordo totalmente" e o ponto 5, "concordo totalmente" (WANG; KROSNICK, 2020).

Inicialmente foi solicitado aos estudantes para utilizar como referência uma única disciplina ao responder a pesquisa. O questionário compreendia, ainda, uma questão inicial sobre a metodologia predominante na disciplina considerada e por fim, questões acerca do perfil dos respondentes.

\section{ANÁLISE DE DADOS}

Para testar as hipóteses do modelo de pesquisa, o estudo utilizou-se da técnica de mínimos quadrados parciais (PLS), um método de modelagem de equações estruturais baseado em variância (SEM). O PLS permite, simultaneamente, a avaliação da confiabilidade e a validade das medidas de construtos teóricos (modelo estrutural) e a estimativa das relações entre esses construtos (modelo medida). O uso do PLS-SEM é a técnica mais apropriada para este estudo: $i$ ) o objetivo do estudo é a predição das variáveis dependentes; e ii) o modelo de pesquisa é consideravelmente complexo de acordo com o tipo de relacionamento nas hipóteses (primeira ordem e segunda ordem) (HAIR et al., 2016). Este estudo utilizou o software SmartPLS 2.0 (HAIR et al., 2016) para a análise dos dados. 


\section{Resultados}

\section{MODELO DE MENSURAÇÃO}

De acordo com Hair et al. (2016), o modelo de mensuração deve ser avaliado inicialmente buscando-se detectar a validade e confiabilidade dos dados. Os resultados são apresentados na Tabela 2. A confiabilidade dos dados foi atestada com base na confiabilidade composta (CC) e no Alpha de Cronbach (a). Nota-se que os constructos apresentaram, em sua maior parte, valor superior a .70, recomendado por Hair et al. (2016). Ainda de acordo com esses autores, estudos exploratórios aceitam valores superiores a .60 para o Alpha (relacionamento). Por se tratar de uma primeira aplicação em uma amostra de estudantes brasileiros, aceita-se esse valor, uma vez que a confiabilidade composta apresentou resultado aceitável.

A validade convergente foi atestada a partir do valor da variância extraída superior a .50 (HAIR et al., 2016). Ainda notam-se valores aceitáveis das cargas fatoriais para atestar a validade convergente (HAIR et al., 2016).

Tabela 2 Modelo de mensuração

\begin{tabular}{|c|c|}
\hline \multicolumn{2}{|l|}{ Coprodução } \\
\hline Conhecimento compartilhado & $E=.764 \alpha=.846$ \\
\hline $\begin{array}{l}\text { O professor foi aberto às minhas ideias e sugestões sobre o método } \\
\text { de ensino existente. }\end{array}$ & .858 \\
\hline $\begin{array}{l}\text { O professor forneceu ilustrações e informações suficientes para que } \\
\text { eu possa entender. }\end{array}$ & .896 \\
\hline $\begin{array}{l}\text { Eu gostaria de contribuir com minhas ideias e sugestões com o pro- } \\
\text { fessor, a fim de ajudar a melhorar seus métodos de ensino. }\end{array}$ & * \\
\hline $\begin{array}{l}\text { O professor me proporcionou ambiente e oportunidade adequados } \\
\text { para oferecer sugestões e ideias. }\end{array}$ & .868 \\
\hline Equidade $\quad \mathrm{CC}=.917 \mathrm{Al}$ & $E=.735 \alpha=.880$ \\
\hline O professor teve um entendimento fácil sobre minhas preferências. & .832 \\
\hline $\begin{array}{l}\text { Os métodos aplicados nas aulas do professor estão alinhados com os } \\
\text { meus objetivos (ou seja, do jeito que eu gostaria que eles fossem). }\end{array}$ & .849 \\
\hline
\end{tabular}


O professor considerou o meu papel tão importante quanto o seu no processo de ensino.

Nós compartilhamos um papel igual na determinação do resultado final do processo.

Interação $\mathrm{CC}=.869$ AVE $=.636 \alpha=.794$

Durante o processo, eu pude expressar convenientemente meus conhecimentos específicos.

O professor transmitiu aos seus alunos as informações relevantes relacionadas ao método de ensino utilizado.

O professor permitiu a interação suficiente dos alunos com seu método de ensino e nos processos aplicados (desenvolvimento da aula, assistência a outros alunos, etc.)

Para obter o máximo benefício do método aplicado, tive que desempenhar um papel proativo durante minha interação (ou seja, tive que aplicar minha habilidade, conhecimento, tempo, etc.).

\section{Valor em uso}

\section{Experiência}

CC $=.838$ AVE $=.639 \alpha=.713$

Foi uma experiência memorável para mim. .880

Dependendo da natureza da minha participação, minhas experiências no processo podem ser diferentes de outros alunos.

.622

Foi possível para os alunos melhorar o processo de aprendizagem experimentando coisas novas.

.868

Personalização

$\mathrm{CC}=.832$ AVE $=.558 \alpha=.732$

O benefício e o valor do método de ensino dependem do aluno e da condição de exposição pelo professor.

O professor tentou atender às necessidades individuais de cada um de seus alunos.

Diferentes alunos, dependendo de suas preferências se envolvem diferentemente no processo de aprendizagem.

O professor proporcionou uma boa experiência geral, além do benefício de aprendizagem.

Relacionamento $\mathrm{CC}=.803 \mathrm{AVE}=.509 \alpha=.675$

A simplificação do professor é necessária para que os alunos aproveitem plenamente o conteúdo exposto. 
Eu senti dedicação do professor na exposição do conteúdo proposto. .785

Geralmente existia um grupo, uma comunidade ou uma rede de alunos que são fãs do professor.

O Professor foi reconhecido porque seus alunos geralmente divulgam atividades positivas sobre seus métodos de ensino em suas redes sociais.

\section{Engajamento}

\section{Entusiasmo}

$$
\mathrm{CC}=.893 \mathrm{AVE}=.676 \alpha=.838
$$

Gosto de passar boa parte do meu tempo livre pensando sobre a disciplina.

Eu sou entusiasmado em relação às aulas da disciplina. .877

Vou sentir falta das aulas da disciplina quando estas acabarem. .886

Eu me sinto bem no ambiente de sala de aula.

.768

\section{Atenção} $\mathrm{CC}=.914$ AVE $=.726 \alpha=.874$

Eu presto bastante atenção em temáticas relacionadas a esta disciplina. .827

Eu gosto de saber mais sobre esta disciplina. .858

Dedico uma porção significativa de atenção a esta disciplina. .856

Eu me concentro em aspectos relacionados a esta disciplina.

\section{Interação social}

$$
\text { CC }=.837 \text { AVE }=.569 \alpha=.740
$$

De forma geral, eu gosto de me envolver em debates da turma ou do grupo desta disciplina.

Eu gosto de interagir com pessoas que pensam como eu nas aulas desta disciplina.

Em geral, gosto muito de trocar ideias com outras pessoas nesta turma ou no grupo.

As opiniões dos meus colegas me influenciam sobre minha percepção sobre a disciplina.

Notas: * Item excluído devida baixa carga fatorial (>.1)

Fonte: elaborado pelos autores

Para testar a validade discriminante dos constructos utilizou-se o critério de Fornell-Larcker, conforme Tabela 3. Nota-se que o valor da raiz da variância extraída foi, em geral, superior ao da correlação entre os constructos (FORNELL; LAR- 
CKER, 1981). Ainda verificou o critério de cargas cruzadas. Nesse método, a carga fatorial de um item deve ser superior em seu constructo do que em outros (HAIR et al., 2016). Reitera-se que os modelos aqui utilizados são hierárquicos e reflexivos, ou seja, espera-se uma elevada correlação entre os itens e os constructos (HAIR et al., 2018). Todavia, com base em ambos os critérios sugeridos, para modelagem em regressões baseadas na variância se obtém a validade discriminante dos dados.

Tabela 3 Validade discriminante

\begin{tabular}{|c|c|c|c|c|c|c|c|c|c|c|c|}
\hline Constructos & $\mathbf{M}$ & SD & 1 & 2 & 3 & 4 & 5 & 6 & 7 & 8 & 9 \\
\hline 1 - Atenção & 4.01 & .82 & .852 & & & & & & & & \\
\hline 2 - Conhecimento & 4.20 & .89 & .378 & .874 & & & & & & & \\
\hline 3 - Entusiasmo & 3.58 & .96 & .599 & .543 & .822 & & & & & & \\
\hline 4 - Equidade & 3.91 & .93 & .391 & .772 & .523 & .857 & & & & & \\
\hline 5 - Experiência & 4.08 & .81 & .370 & .664 & .527 & .670 & .799 & & & & \\
\hline 6 - Interação & 4.18 & .75 & .420 & .759 & .555 & .796 & .706 & .798 & & & \\
\hline 7 - Interação social & 3.57 & .84 & .405 & .187 & .391 & .234 & .279 & .285 & .754 & & \\
\hline 8 - Personalização & 4.20 & .72 & .407 & .713 & .568 & .737 & .643 & .696 & .251 & .747 & \\
\hline 9 - Relacionamento & 3.97 & .77 & .348 & .636 & .565 & 639 & .631 & .662 & .261 & .681 & .713 \\
\hline
\end{tabular}

Notas: Valores em negrito na diagonal representam a raiz quadrada da variância média extraída, os valores abaixo da diagonal representam a correlação entre os constructos.

Fonte: elaborado pelos autores

\section{MODELO ESTRUTURAL}

O resultado do modelo estrutural é representado na tabela 4. Observa-se que todos os constructos de primeira ordem apresentaram significância, confirmando assim a estrutura de coprodução, valor em uso e engajamento.

Uma vez que se confirme a estrutura dos dados, através da validade e confiabilidade, realiza-se o teste das hipóteses propostas. De acordo com Hair et al. (2016), deve-se utilizar a técnica de Bootstrapping (5000 resample) para gerar erros padrão e estatística t, o que permite avaliar a significância estatística das relações consideradas no modelo. A hipótese 1 aponta que a coprodução aumenta o engajamento. A partir dos resultados do estudo $(\beta=.184, t=2.02 ; p<.05)$, a hipótese 1 
é confirmada. Da mesma forma, o valor em uso gera um impacto positivo e significativo no engajamento $(\beta=.427, t=4.80 ; p<.001)$, confirmando assim a hipótese 2. Ambas as variáveis explicaram $35 \%$ do engajamento dos alunos com a disciplina. As variáveis de controle testadas (idade, semestre e gênero) não apresentaram diferenças significantes $(p=n s)$.

Tabela 4 Teste de hipóteses

\begin{tabular}{|c|c|c|c|c|c|c|c|}
\hline & Relação & $B$ & SE & $\boldsymbol{\beta}$ & t-value & Sig. & $\mathbf{R}^{2}$ \\
\hline \multirow{3}{*}{$\begin{array}{l}2^{\mathrm{a}} \text { ordem } \\
\text { Coprodução }\end{array}$} & Conhecimento & .903 & .016 & .903 & 58.09 & .001 & .815 \\
\hline & Equidade & .939 & .008 & .938 & 117.28 & .001 & .881 \\
\hline & Interação & .924 & .011 & .923 & 84.05 & .001 & .853 \\
\hline \multirow{3}{*}{$\begin{array}{l}2^{\mathrm{a}} \text { ordem } \\
\text { Valor em uso }\end{array}$} & Experiência & .853 & .020 & .853 & 43.84 & .001 & .727 \\
\hline & Personalização & .896 & .013 & .897 & 68.48 & .001 & .803 \\
\hline & Relacionamento & .879 & .015 & .879 & 59.98 & .001 & .772 \\
\hline \multirow{3}{*}{$\begin{array}{c}2^{\mathrm{a}} \text { ordem } \\
\text { Engajamento }\end{array}$} & Entusiasmo & .859 & .017 & .861 & 50.53 & .001 & .739 \\
\hline & Interação social & .665 & .042 & .667 & 15.93 & .001 & .442 \\
\hline & Atenção & .866 & .019 & .866 & 45.77 & .001 & .750 \\
\hline Hipótese 1 & $\begin{array}{c}\text { Coprodução } \rightarrow \\
\text { Engajamento }\end{array}$ & .184 & .091 & 182 & 2.02 & .050 & .302 \\
\hline Hipótese 2 & $\begin{array}{c}\text { Valor em uso } \rightarrow \\
\text { Engajamento }\end{array}$ & .427 & .089 & .430 & 4.80 & .001 & .341 \\
\hline
\end{tabular}

Notas: $p<.05 .=t(.05,4999)=1.645 ; p<.01 .=t(.01,4999)=2.327 ; p<.001 . t(.001,4999)=3.092 . \mathrm{R}^{2}$ $=$ coeficiente de determinação.

Fonte: elaborado pelos autores

A terceira hipótese foi testada realizando-se regressões por grupos (metodologia ativa vs. não ativa), para posteriormente serem comparadas as regressões (HAIR et al., 2016). Nota-se que a relação entre valor em uso e engajamento não apresentou diferença significativa $(p=n s)$ em ambas as metodologias, levando a rejeição da $\mathrm{H}_{3 \mathrm{a}}$. Contudo, a relação entre coprodução e engajamento apresentou resultados distintos conforme a metodologia de ensino $(p<.001)$. Para metodologia 
ativa os resultados foram, inclusive insignificantes $(\beta=.064, t=.647 ; p=n s)$, apresentando-se suporte para a $\mathrm{H}_{3 \mathrm{~b}}$.

\section{DISCUSSÃO}

A primeira contribuição da presente pesquisa é demonstrar a eficácia de uma mensuração reflexiva à formulação de Ranjan e Read (2016). Com isso, amplia-se a oportunidade de distintas mensurações para novas pesquisas. Outra contribuição do estudo foi demonstrar que os constructos formadores da cocriação são influenciadores do engajamento dos estudantes. Observa-se uma série de comportamentos decorrentes do engajamento, que são benéficos à empresa, por exemplo, valor intrínseco, extrínseco (VIVEK et al., 2014) e feedback (GRILLO et al., 2014). Identifica-se uma cadeia na qual a partir do incentivo à cocriação de valor, além dos benefícios já conhecidos, por exemplo satisfação e lealdade atitudinal do consumidor (COSSÍO-SILVA et al., 2016; FRIO; BRASIL, 2016), irá gerar um maior engajamento dos estudantes e, por consequência, outros ganhos à empresa.

Os resultados demonstram ainda que uma metodologia de ensino não ativa leva o estudante a uma maior busca pela coprodução para se engajar na disciplina e melhorar o desempenho geral. Nota-se que o estudante, em geral, não busca um papel passivo e sim, ativo nos processos de ensino, devendo essa visão imperar nas relações de cocriação de valor (PRAHALAD; RAMASWAMY, 2004; VARGO; LUSCH, 2016). Por esse motivo, é importante que as instituições de ensino superior tenham um profundo entendimento da responsabilidade compartilhada entre os participantes (estudantes e professores) e enfatizem ainda mais a importância da responsabilidade do aluno ao desempenhar um papel ativo na definição do valor de suas experiências (DOLLINGER; LODGE; COATES, 2018).

\section{Considerações finais}

O presente estudo buscou analisar o efeito da cocriação de valor em sala de aula como um antecedente do engajamento dos estudantes de ensino superior. $\mathrm{O}$ estudo permitiu identificar como os alunos cocriam valor para a melhoria da experiência de sala de aula. O ensino nunca foi percebido como um produto independente; sem- 
pre foi uma interação cocriada entre o aluno e professor e, como tal, tem uma fundamentação baseada em relacionamento (KELLEY; DONNELLY JR; SKINNER, 1990).

É possível observar que os comportamentos de cocriação dos alunos (coprodução e valor em uso) auxiliam no aumento do engajamento com a disciplina. O maior engajamento dos estudantes na disciplina auxilia na construção de melhor dinâmica e desempenho dos acadêmicos. O modelo detalha especificamente como a cocriação de valor pode agregar valor ao engajamento na disciplina, tanto para o professor quanto para os alunos nos quais a instituição depende (DOLLINGER; LODGE; COATES, 2018).

Além disso, no presente estudo a análise foi baseada em dados de cocriação, um axioma da lógica de serviço dominante. Nota-se que Vargo e Lusch (2016) acreditam que lógica de serviço dominante está avançando para o desenvolvimento de uma teoria geral de mercado. Esse estudo contribui à construção dessa perspectiva.

Os resultados do presente estudo apontam para um trade-off. Os resultados da análise apontam que os professores e instituições devem escolher entre incentivar a cocriação de valor do estudante ou implantar metodologias ativas, tendo em vista o engajamento na disciplina. Os resultados apontam que os impactos da coprodução de valor no engajamento só serão atingidos para metodologias não ativas. O impacto do valor em uso repete os resultados em ambas as metodologias.

Do ponto de vista metodológico, este estudo amplia as possibilidades de utilização da escala de Ranjan e Read (2016). Nota-se que a mesma foi testada e validade usando mensurações reflexivas e não formativa, conforme originalmente concebido. Da mesma forma, se demonstrou que coprodução e valor em uso podem ser utilizados de maneira independente e também reflexiva. Os dados do presente estudo confirmaram a estrutura proposta por Vivek et al. (2014) para mensurar o engajamento. Essa estrutura já havia sido validada no Brasil (GRILLO et al., 2014) e demonstrou novamente sua eficácia e estrutura. Ademais, esses modelos apresentaram eficácia ao serem analisados no contexto de sala de aula e participação do estudante.

\section{IMPLICAÇÕES GERENCIAIS}

Os resultados da pesquisa auxiliam os gestores universitários e professores demonstrando que o incentivo à cocriação de valor pode ser benéfico a uma melhor dinâmica da disciplina. Uma vez que a cocriação de valor se demostrou um forte 
previsor para o engajamento com a disciplina. Além disso, observa-se que o valor é cocriado por uma rede de atores, sendo que nesse caso universidade deve fazer a oferta a ser avaliada pelos alunos (VARGO; LUSCH, 2016), correspondendo assim a uma contribuição para ambos.

Sugere-se aos docentes e gestores das instituições de ensino, a partir dos dados aqui obtidos, que busquem incentivar os alunos à cocriação de valor, lhe gerando o papel de protagonista, dados que o presente estudo demostrou a participação do estudante no processo de ensino aumenta o seu engajamento com a disciplina. Por outro lado, não foi observado que a metodologia ativa gera maior engajamento para alunos que buscam uma maior participação nos processos, dado que sua percepção de valor é gerada a partir de sua participação na disciplina.

Apesar da relevância e resultados recentes identificados sobre a utilização de metodologias ativas (GUERRA; TEIXEIRA, 2016, ELSHARNOUBY, 2015; PAIVA et al., 2016), alguns docentes e disciplinas acabam exigindo métodos mais tradicionais de estudo. Ao incentivar o aluno a cocriar valor, através da interação e autonomia, as instituições tendem a apresentar alunos mais engajados, independentemente da metodologia empregada.

\section{LIMITAÇÕES E SUGESTÃO DE PESQUISAS FUTURAS}

O presente estudo foi o primeiro a avaliar o papel da cocriação de valor do aluno no engajamento, considerando o tipo de metodologia empregada como moderadora. IA escolha empregadas neste estudo geram algumas limitações que deverão ser exploradas em novos estudos. A análise empregada foi de coleta transversal em apenas uma disciplina. Novos estudos devem comparar os resultados entre disciplinas com o mesmo conteúdo e com metodologias diferentes.

No presente estudo não se controlou os tipos de disciplinas (teóricas, aplicadas, etc.). O controle dessa variável pode elucidar distintos resultados em novas análises. Outro ponto importante, seria avaliar como disciplinas iguais com diferentes docentes tem impacto no engajamento dos estudantes. Considerou-se apenas o engajamento do aluno como variável dependente. Futuras investigações poderiam investigar os impactos da cocriação e da metodologia no desempenho do acadêmico (AGUNDES; LUCE; RODRIGUEZ ESPINAR, 2014), gerando nova luz no papel de ambas para a formação do acadêmico. 
Os dados da presente pesquisa foram coletados junto a acadêmicos de instituições comunitária. Novas pesquisas devem ampliar e controlar o tipo de universidade (comunitária, pública ou privada). Novas pesquisas deveriam considerar a aplicação de metodologia experimental, utilizando disciplinas de mesma natureza com o mesmo docente, porém com metodologias de ensino diferente (metodologia ativa vs. tradicional) sendo possível testar a causalidade entre a cocriação de valor e as metodologias empregadas.

Foram escolhidas para o presente estudo as concepções de cocriação de valor (RANJAN; READ, 2016) e de engajamento (VIVEK et al., 2014). Observa-se que existem outras medidas para a mensuração desses constructos. Além disso, o presente estudo baseou-se em modelos exclusivamente hierárquicos. Novos estudos devem buscar testar as relações aqui identificadas com outras medidas de mensuração e constructos unidimensionais, buscando entender a replicabilidade dos resultados.

\section{Referências}

BERBEL, N. A. N. As metodologias ativas e a promoção da autonomia de estudantes. Semina: Ciências Sociais e Humanas, v. 32, n. 1, p. 25-40, 2011. DOI: http://dx.doi.org/10.5433/1679-0383.2011 v32n1p25

BONSU, S. K.; DARMODY, A. Co-creating Second Life: Market-Consumer Cooperation in Contemporary Economy. Journal of Macromarketing, v. 28, n. 4, p. 355-368, 1 dez. 2008. DOI: https://doi. org/10.1177/0276146708325396

BOVILL, C. Co-creation in learning and teaching: the case for a whole-class approach in higher education. Higher Education, v. 79, n. 6, p. 1023-1037, 2020. DOI: https://doi.org/10.1007/s10734-019-00453-w BRODIE, R. J. et al. Customer Engagement: Conceptual Domain, Fundamental Propositions, and Implications for Research. Journal of Service Research, v. 14, n. 3, p. 252-271, 6 jul. 2011. DOI: https://doi. org/10.1177/1094670511411703

BUSSER, J. A.; SHULGA, L. V. Co-created value: Multidimensional scale and nomological network. Tourism Management, v. 65, p. 69-86, 2018. DOI: https://doi.org/10.1016/j.tourman.2017.09.014 COSSíO-SILVA, F.-J. et al. Value co-creation and customer loyalty. Journal of Business Research, v. 69, n. 5, p. 1621-1625, 2016. DOI: https://doi.org/10.1016/j.jbusres.2015.10.028

DEBERRY-SPENCE, B. Consumer creations of product meaning in the context of African-style clothing. Journal of the Academy of Marketing Science, v. 36, n. 3, p. 395-408, 2008. DOI: https://doi. org/10.1007/s11747-007-0057-x 
Cocriação de Valor em Sala de Aula como um Antecedente do Engajamento dos Estudantes de Instituição de Ensino Superior Value Co-creation in the Classroom as an Antecedent of Student Engagement of Higher Education Institution

Clécio Falcão Araujo | Ricardo Saraiva Frio | Caroline da Rosa | Patricia Rodrigues da Silva

DESSART, L.; VELOUTSOU, C.; MORGAN-THOMAS, A. Capturing consumer engagement: duality, dimensionality and measurement. Journal of Marketing Management, v. 32, n. 5-6, p. 399-426, 23 mar. 2016. DOI: https://doi.org/10.1080/0267257X.2015.1130738

DOLLINGER, M.; LODGE, J.; COATES, H. Co-creation in higher education: towards a conceptual model. Journal of Marketing for Higher Education, v. 28, n. 2, p. 210-231, 3 jul. 2018. DOI: https://doi.org/10 $.1080 / 08841241.2018 .1466756$

ELSHARNOUBY, T. H. Student co-creation behavior in higher education: the role of satisfaction with the university experience. Journal of Marketing for Higher Education, v. 25, n. 2, p. 238-262, 3 jul. 2015. DOI: https://doi.org/10.1080/08841241.2015.1059919

FAGUNDES, Caterine Vila; LUCE, Maria Beatriz; RODRIGUEZ ESPINAR, Sebastián. O desempenho acadêmico como indicador de qualidade da transição Ensino Médio-Educação Superior. Ensaio: avaliação e políticas públicas em educação, 2014, 22.84: 635-669.

FIDALGO-BLANCO, A. et al. Micro flip teaching-An innovative model to promote the active involvement of students. Computers in Human Behavior, v. 72, p. 713-723, 2017. DOI: https://doi.org/10.1016/j. chb.2016.07.060

FORNELL, C.; LARCKER, D. F. Evaluating Structural Equation Models with Unobservable Variables and Measurement Error. Journal of Marketing Research, v. 18, n. 1, p. 39-50, 1 fev. 1981. DOI: https://doi. org/10.2307/3151312

FRIO, R. S.; BRASIL, V. S. Comportamento de cocriação de valor do consumidor como antecedente da satisfação e lealdade. REGE - Revista de Gestão, v. 23, n. 2, p. 135-147, 2016. DOI: https://doi. org/10.1016/j.rege.2015.12.003

FROW, P. et al. Managing Co-creation Design: A Strategic Approach to Innovation. British Journal of Management, v. 26, n. 3, p. 463-483, 1 jul. 2015. DOI: https://doi.org/10.1111/1467-8551.12087

GIBBERT, M.; LEIBOLD, M.; PROBST, G. Five Styles of Customer Knowledge Management, and How Smart Companies Use Them To Create Value. European Management Journal, v. 20, n. 5, p. 459-469, 2002. DOI: https://doi.org/10.1016/S0263-2373(02)00101-9

GÓMEZ, Á. I. P. Un aprendizaje diverso y relevante. Cuadernos de pedagogía, v. 311, p. 66-70, 2002.

GRILLO, T. L. H. et al. Cocriação de valor com alunos: uma análise da influência social e do engajamento na disciplina como antecedentes de feedback do estudante. Administração: Ensino e Pesquisa, v. 15, n. 3, p. 533-559, 2014. DOI: https://doi.org/10.13058/raep.2014.v15n3.15

GRÖNROOS, C. Service logic revisited: who creates value? And who co-creates? European Business Review, v. 20, n. 4, p. 298-314, 1 jan. 2008. DOI: https://doi.org/10.1108/09555340810886585

GRÖNROOS, C.; VOIMA, P. Critical service logic: making sense of value creation and co-creation. Journal of the Academy of Marketing Science, v. 41, n. 2, p. 133-150, 2013. DOI: https://doi.org/10.1007/ s11747-012-0308-3

GUERRA, Cicero Jose Oliveira; TEIXEIRA, Aridelmo José Campanharo. Os impactos da adoção de metodologias ativas no desempenho dos discentes do curso de ciências contábeis de instituição de ensino superior mineira. Revista de Educação e Pesquisa em Contabilidade, 2016, 10.4: 380-397.

HAIR, J. F. et al. A primer on partial least squares structural equation modeling (PLS-SEM). [s.I.] Sage publications, 2016.

HAIR, J. F. et al. Multivariate Data Analysis. [s.I.] Cengage, 2018.

HOFSTATTER, C. R. Estudo dos efeitos da co-criação de valor no desempenho percebido, satisfação e lealdade. 2010. 
Cocriação de Valor em Sala de Aula como um Antecedente do Engajamento dos Estudantes de Instituição de Ensino Superior Value Co-creation in the Classroom as an Antecedent of Student Engagement of Higher Education Institution

Clécio Falcão Araujo | Ricardo Saraiva Frio | Caroline da Rosa | Patricia Rodrigues da Silva

KELLEY, S. W.; DONNELLY JR, J. H.; SKINNER, S. J. Customer participation in service production and delivery. Journal of Retailing, v. 66, n. 3, p. 315, 1990.

MATZEMBACHER, D. E.; GONZALES, R. L.; DO NASCIMENTO, L. F. M. From informing to practicing: Students' engagement through practice-based learning methodology and community services. The International Journal of Management Education, v. 17, n. 2, p. 191-200, 2019. DOI: https://doi. org/10.1016/j.jime.2019.03.002

MAVONDO, F. T.; TSARENKO, Y.; GABBOTT, M. International and Local Student Satisfaction: Resources and Capabilities Perspective. Journal of Marketing for Higher Education, v. 14, n. 1, p. 41-60, 8 nov. 2004. DOI: https://doi.org/10.1300/J050v14n01_03

MERZ, M. A.; ZARANTONELLO, L.; GRAPPI, S. How valuable are your customers in the brand value co-creation process? The development of a Customer Co-Creation Value (CCCV) scale. Journal of Business Research, v. 82, p. 79-89, 2018. DOI: https://doi.org/10.1016/j.jbusres.2017.08.018

OGUNMOKUN, O. A. et al. Consumer well-being through engagement and innovation in higher education: A conceptual model and research propositions. Journal of Public Affairs, v. 21, n. 1, p. e2100, 3 fev. 2021. DOI: https://doi.org/10.1002/pa.2100

PAIVA, M. R. F. et al. Metodologias ativas de ensino-aprendizagem: revisão integrativa. SANARE-Revista de Políticas Públicas, v. 15, n. 2, 2016.

PRAHALAD, C. K.; RAMASWAMY, V. Co-creation experiences: The next practice in value creation. Journal of Interactive Marketing, v. 18, n. 3, p. 5-14, 2004. DOI: https://doi.org/10.1002/dir.20015

RANJAN, K. R.; READ, S. Value co-creation: concept and measurement. Journal of the Academy of Marketing Science, v. 44, n. 3, p. 290-315, 2016. DOI: https://doi.org/10.1007/s11747-014-0397-2

SEGURA-ROBLES, A.; PARRA-GONZÁLEZ, M.; GALLARDO-VIGIL, M. Bibliometric and collaborative network analysis on active methodologies in education. Journal of New Approaches in Educational Research (NAER Journal), v. 9, n. 2, p. 259-274, 2020. DOI: https://doi.org/10.7821/naer.2020.7.575 TOMMASETTI, A.; TROISI, O.; VESCI, M. Measuring customer value co-creation behavior. Journal of Service Theory and Practice, v. 27, n. 5, p. 930-950, 11 set. 2017. DOI: https://doi.org/10.1108/JSTP10-2015-0215

VARGO, S. L.; LUSCH, R. F. Evolving to a new dominant logic for marketing. Journal of marketing, v. 68, n. 1, p. 1-17, 2004. DOI: https://doi.org/10.1509/jmkg.68.1.1.24036

VARGO, S. L.; LUSCH, R. F. Institutions and axioms: an extension and update of service-dominant logic. Journal of the Academy of Marketing Science, v. 44, n. 1, p. 5-23, 2016. DOI: https://doi.org/10.1007/ s11747-015-0456-3

VARGO, S. L.; LUSCH, R. F. Service-dominant logic 2025. International Journal of Research in Marketing, v. 34, n. 1, p. 46-67, 2017. DOI: https://doi.org/10.1016/j.jiresmar.2016.11.001

VIVEK, S. D. et al. A Generalized Multidimensional Scale for Measuring Customer Engagement. Journal of Marketing Theory and Practice, v. 22, n. 4, p. 401-420, 1 out. 2014. DOI: https://doi.org/10.2753/ MTP1069-6679220404

WANG, R.; KROSNICK, J. A. Middle alternatives and measurement validity: a recommendation for survey researchers. International Journal of Social Research Methodology, v. 23, n. 2, p. 169-184, 3 mar. 2020. DOI: https://doi.org/10.1080/13645579.2019.1645384

ZEITHAML, V. A. et al. Three decades of customer value research: paradigmatic roots and future research avenues. Journal of Service Research, v. 23, n. 4, p. 409-432, 2020. DOI: https://doi. org/10.1177/1094670520948134 